\title{
Childbearing and postpartum inaugural episode of bipolar disorder
}

A.V. Costa ${ }^{1}$, A. Samico ${ }^{2}$, S. Mendes ${ }^{1}$, A.S. Pires ${ }^{1}$, S. Melo ${ }^{1}$, A. Venâncio ${ }^{2}$, A. Horta ${ }^{2}$ ${ }^{1}$ Hospital Center of Vila Nova de Gaia/Espinho, Child and Adolescent Psychiatry, Vila Nova de Gaia, Portugal. ${ }^{2}$ Hospital Center of Vila Nova de Gaia/Espinho, Psychiatry and Mental Health, Vila Nova de Gaia, Portugal.

\section{Background and Objectives:}

The postpartum period is of great vulnerability to the development of psychopathology, especially in what regards to mood disorders.

Bipolar disorder (BD) commonly occurs in women during this period and some studies suggest that the presence of postpartum psychopathology is a bipolarity's hallmark. About $20 \%$ of women who screen positive for postpartum depression have BD.

\begin{abstract}
We intend to evaluate women of childbearing age diagnosed with BD identifying those whose inaugural episode occurred in pregnancy or postpartum period (one year after childbirth); and evaluate the polarity of the first episode, the diagnosis, comorbidities, severity criteria and psychotropic drugs used.
\end{abstract}

Design and Methods: We performed a retrospective survey examining medical records of all patients who met the following inclusion and exclusion criteria:

Patients followed at our Psychiatry hospital center: outpatient or inpatient in the period from 2008 to 2018.

Female patients whose current age varies between 18-38 years.

Patients diagnosed with BD.

Patients were excluded in the absence of data for evaluation in the electronic or physical clinical process

Then we identified those who had the first episode in pregnancy or postpartum period and compared with those in which the inaugural episode occurred unrelated to pregnancy or postpartum period. This study was approved by the Hospital Ethics Committee.

\section{Discussion and Conclusions:}

In our study, depressive episode was the most frequent first manifestation in pregnancy and postpartum period. According to the literature review depression is the most frequent morbidity in postpartum. Distinguishing bipolar from unipolar depression can be challenging. Women experiencing their first episode of postpartum depression should be considered for a possible diagnosis of BD and should be monitored closely.

Limitations of the study include retrospective clinical trial through the analyze of records made in the physical and electronic processes and small sample size $(n=20)$. Some patients may not have been identified due to lack of diagnostic classification in the medical records and the BD has a bimodal peak of maniac/hippomaniac presentation, so we do not have data to evaluate those whose symptomatology may be manifest at an older age and some women may be misdiagnosed as major depressive disorder.

\section{Results:}

Of the total number of women identified with a diagnosis of BD $(n=20), 30 \%$ had a first contact with Psychiatry in pregnancy $(16.7 \%)$ or first year postpartum $(83.3 \%)$.

In $83.3 \%$ of the cases the inaugural episode was of postpartum depression with an antidepressant at an early stage.

\begin{tabular}{|c|c|c|c|}
\hline & $\begin{array}{l}\text { Total BD } \\
\text { female } \\
\text { patients }\end{array}$ & $\begin{array}{l}\text { BD inaugural } \\
\text { episode in } \\
\text { postpartum or } \\
\text { pregnancy period }\end{array}$ & $\begin{array}{l}\text { BD inaugural } \\
\text { episode without } \\
\text { postpartum or } \\
\text { pregnancy period }\end{array}$ \\
\hline Age (median $[|Q 1| Q 3$,$] )$ & $33[27,26]$ & $35[31,37]$ & $31[26,36]$ \\
\hline \multicolumn{4}{|l|}{ Marital Status } \\
\hline Single (\%) & 60 & 16.7 & 78.6 \\
\hline Married (\%) & 25 & 33.3 & 21.4 \\
\hline Divorced (\%) & 15 & 50 & 0 \\
\hline \multicolumn{4}{|l|}{ Scholarity } \\
\hline 4th year (\%) & 10 & 0 & 14.3 \\
\hline 9th year (\%) & 25 & 33.3 & 21.4 \\
\hline 12th year (\%) & 40 & 50 & 35.7 \\
\hline Graduation (\%) & 25 & 16.7 & 28.6 \\
\hline \multicolumn{4}{|l|}{ Household } \\
\hline Family of origin (\%) & 35 & 16.7 & 42.9 \\
\hline Alone (\%) & 10 & 0 & 14.3 \\
\hline Formation of couple (\%) & 15 & 0 & 21.4 \\
\hline Small children (\%) & 30 & 66.7 & 14.3 \\
\hline Grown children (\%) & 10 & 16.7 & 7.1 \\
\hline Positive Family History (\%) & 25 & 33.3 & 21.4 \\
\hline \multicolumn{4}{|l|}{ Diagnosis } \\
\hline BP type 1 (\%) & 80 & 83.3 & 78.6 \\
\hline BP type $2(\%)$ & 20 & 16.7 & 21.4 \\
\hline Comorbidity disorder (\%) & 25 & 0 & 36.7 \\
\hline \multicolumn{4}{|c|}{ Number of hospitalizations } \\
\hline $0(\%)$ & 10 & 7.14 & 16.7 \\
\hline $1(\%)$ & 50 & 50 & 50 \\
\hline $2(\%)$ & 15 & 14.3 & 16.7 \\
\hline$>3(\%)$ & 20 & 21.4 & 16.7 \\
\hline Positive suicide attempts (\%) & 30 & 16.7 & 35.7 \\
\hline $\begin{array}{l}\text { Age of first episode (median } \\
{[(\mathrm{Q} 1, \mathrm{QQ} 3))}\end{array}$ & $25[19,30]$ & $27[19,31]$ & $24[19,28]$ \\
\hline \multicolumn{4}{|l|}{ Type of first episode } \\
\hline Depressive (\%) & 60 & 83.3 & 41.1 \\
\hline Manic (\%) & 25 & 0 & 35.7 \\
\hline Mixed (\%) & 5 & 16.7 & 0 \\
\hline \multicolumn{4}{|l|}{ Medication history } \\
\hline $\begin{array}{l}\text { Antidepressant followed } \\
\text { by mood stabilizer (\%) }\end{array}$ & 55 & 83.3 & 42.9 \\
\hline $\begin{array}{l}\text { Mood stabilizer followed } \\
\text { by antidepressant (\%) }\end{array}$ & 4 & 0 & 14.3 \\
\hline Only mood stabilizer (\%) & 25 & 16.7 & 28.6 \\
\hline
\end{tabular}

The groups were not significantly different regarding the presence of comorbidities, polarity of the first episode, criteria of severity and age of diagnosis; reflecting the low number of the sample; being different in what concerns the marital state.

The postpartum period represents an increased risk for onset and relapse of BD.

International guidelines recommending both a preconception counselling and appropriate pregnancy planning for women with a diagnosis of $\mathrm{BD}$, a screening of pregnant women for BD or for risk factors (family or personal history) and screen all pregnant and postpartum women for depression. Some studies suggest screening all women with postpartum depression for bipolar disorder.

Some factors that increase risk such sleep deprivation and no pleasure time in early postpartum should be target for early primary prevention.

Screening enables timely diagnosis and treatment to be made, allowing a better satisfaction in the role of mother and prevent better mother-child dyad health care (the impact of unipolar or bipolar postpartum depression on the child psychoactive development and mother/child relashionship is substantial since these mothers may not be able to provide the nurture and support that their babies require that interpose in mother-child attachment), as well as preventing physical risks for baby and mother. 